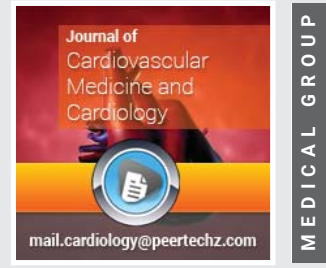

\title{
Genetic Variants of Abo Blood Group and Coronary Artery Disease
}

\section{PK Chawla' ${ }^{1}$ CK Ponde ${ }^{2}$, RM Rajani², 'AS Deshpande ${ }^{3}$, RB Sawant ${ }^{4}$ and TF Ashavaid ${ }^{1,5 *}$}

${ }^{1}$ Research Laboratories, PD Hinduja National Hospital and Medical Research Centre, Mahim, Mumbai-400016, India

${ }^{2}$ Department of Cardiology, PD Hinduja National Hospital and Medical Research Centre, Mahim, Mumbai-400016, India

${ }^{3}$ Department of Transfusion Medicine, PD Hinduja National Hospital and Medical Research Centre, Mahim, Mumbai-400016, India

${ }^{4}$ Department of Laboratory Medicine and Transfusion Medicine, Kokilaben Dhirubhai Ambani Hospital \& Medical Research Centre, Andheri, Mumbai - 400053, India

${ }^{5}$ Department of Laboratory Medicine. P.D. Hinduja National Hospital and Medical Research Centre, Mahim, Mumbai-400016, India

\section{Abstract}

Background: The $A B O$ gene encodes for the blood group antigens which are expressed on the surface of RBCs, platelets and the vascular endothelium. Several recent studies and GWASs have identified $\mathrm{ABO}$ as a locus for thrombosis, myocardial infarction, and multiple cardiovascular risk biomarkers.

Objectives: The objective of the study was to determine the association of genetic variants in the $A B O$ gene with coronary artery disease (CAD)

Study design-setting-patients: A total of 500 subjects including 250 angiographically verified CAD patients' age and gender matched with 250 angiographically verified controls were recruited for the study. Genotyping of variants A2 (deletion of C; rs918130198), B (G803C;rs8176747), 01 (deletion of G; rs8176719), 02 (G802A;rs1286157771) and A1 (wild type) alleles were performed by allele specific PCR and lipid profile, hsCRP \& sICAM1 levels were estimated for all subjects.

Outcome measures: This study will help understand the influence of genetic variations in the ABO genotypes on the risk of CAD amongst Indians.

Findings \& interpretation: Among the blood group alleles, 01 (Cases-32\%; Controls-50\%; $\mathrm{p}=0.009$ ) and the B allele (Cases-34\%; Controls-19\%; $\mathrm{p}=0.01$ ) were significantly associated with $C A D$ while others ( $11, A 2$ and 02 alleles) were insignificant. The 01 allele suggested an atheroprotective role while the $B$ variant was atherogenic. Genotypically, the BB genotype was more prone to develop CAD with a 5 fold increased risk while the 0101 genotype was at least risk protecting the individual by 2 folds. The distributions of remaining genotypic combinations of blood groups were found similar in both the groups. role.

Conclusion: These findings suggest the B blood group individuals especially BB genotypes to be at higher risk for CAD while the 01 allele playing an atheroprotective

\section{Introduction}

Coronary Artery Disease (CAD) is the leading cause of death worldwide responsible for over 7 million deaths annually. In South Asia, deaths due to CAD have increased by $87.8 \%$ between
1990 and 2010, and is predicted to increase further by $50 \%$ by 2030 [1]. India experiences the highest number of potentially productive life years lost due to cardiovascular disease; 9.2 million years in 2000 and is expected to double to 17.9 million years by 2030 [1]. Traditional risk factors of CAD include 
smoking, hypertension, diabetes, family history of CAD and biochemical markers like lipid profile. Genetics confer to about $40-60 \%$ risk of susceptibility to CAD. Genetic studies provide new insights into the pathogenesis of CAD and Myocardial Infarction (MI) [2]. Studies on identification of novel genetic risk markers, exploration of molecular mechanisms by which mutations cause CAD may be important for better refining individuals at risk for $\mathrm{CAD}[3,4]$.

The clinical significance of ABO blood type extends beyond transfusion medicine and solid organ / hematopoietic transplantation. To date, numerous reports have suggested important associations between $\mathrm{ABO}$ blood groups and various diseases e.g., gastric cancer, periodontal diseases and cardiometabolic diseases $[5,6]$. Studies on the associations between cardiovascular disease (CVD) and ABO blood groups have a long history $[7,8]$. However, there is limited consensus at the population level and whether it relates to all disorders equally or predominantly modulates thrombotic pathways and disorders [9]. $\mathrm{ABO}$ blood group antigens encoded by the $A B O$ gene at chromosome 9 are genetically transmitted from generation to generation. There are over 190 alleles defining the variations in the gene and hence tagged as subtypes of $\mathrm{A}$ or $\mathrm{B}$ or $\mathrm{O}$ alleles. Of these the $\mathrm{A} 1, \mathrm{~A} 2, \mathrm{~B}, \mathrm{O} 1$ \& $\mathrm{O} 2$ alleles are the most important ones and are considered to be important representative markers of each A, B or O type blood group [10].

Most studies have agreed the non $\mathrm{O}$ blood group to be at high risk for $\mathrm{CAD}[11,12]$. The $\mathrm{A} / \mathrm{B}$ antigens resemble in structure to several inflammatory markers like adhesion molecules, selectins etc. These antigens thus falsely trigger inflammatory pathways by influencing the plasma levels of soluble forms of inflammatory markers and activating the immune system conferring a higher risk for CAD [9]. Several GWAS have identified the ABO locus to increase soluble levels of adhesion molecules (ICAM1, VCAM1) \& selectins (E-selectin P-selectin) and also a high risk marker for MI [13-15]. In most cases, premature $\mathrm{CAD}$ may be linked to inheritable risk factors, and hence inheritance of the $\mathrm{ABO}$ groups could play an important role in development of premature CAD.

Most studies have associated the serologically determined blood groups with $\mathrm{CAD}$, however, the data on genetics of $\mathrm{ABO}$ blood groups is lacking. Thus, we aimed to investigate the relationship between genetically determined $\mathrm{ABO}$ blood groups

\section{Materials \& methods}

\section{Study group}

The study was a 1:1 case - control study conforming to the ethical guidelines \& approved by the Institutional Review Board of the Hospital. Written informed consent was taken from a total of 500 individuals visiting the P. D. Hinduja Hospital and Medical Research Center's catheterization laboratory enrolled in this study. These included 250 angiographically verified CAD cases (> $50 \%$ stenosis in at least one of the 3 major coronary arteries) age and gender matched with 250 angiographically regarding the magnitude and significance of the $\mathrm{ABO}$ effects and CAD amongst Indians.

confirmed CAD controls (<30\% stenosis) [13]. Subjects with abnormal liver or kidney function were excluded from the study. A detailed proforma with information on demographics presence of coronary risk factors such as diabetes, hypertension, smoking etc., current medication, family history of CAD, as self-reported by patients and previous coronary intervention if any were noted from all the entire study group.

\section{Molecular methods}

DNA Extraction: About $5 \mathrm{ml}$ of venous blood sample was collected from the subjects in EDTA tube (for DNA extraction) and plain tube (for serum). The DNA was extracted by the modified salting out procedure of Miller, et al. [16]. The DNA and serum aliquots were preserved at $-80^{\circ} \mathrm{C}$ until analysis.

PCR and DNA Sequencing: The ABO blood group was determined genetically using the 5 major alleles - A1 (wild type), A2 (deletion of C; rs918130198), B (G803C;rs8176747) O1 (deletion of G; rs8176719) and O2 (G802A; rs1286157771) alleles by conventional PCR methods. With these 5 alleles, an individual can have any one of the 15 possible genotypes e.g a $\mathrm{B}$ blood group individual may be $\mathrm{BO} 1, \mathrm{BO} 2$ or $\mathrm{BB}$ genotype and so on for each blood group type. These genotypes were determined with 2 singleplex and 1 multiplex Allele specific PCRs. For each PCR assay, a master mix (50 $\mu \mathrm{l})$ was prepared consisting of PCR buffer, $\mathrm{MgCl}$ 2, dinucleotide triphosphate mix, specific primers, Distilled water, Taq polymerase and template DNA in specific concentrations as needed. The primer sequences and PCR conditions are described in Supplementary Table 1. The PCR products were run on a standard $3 \%$ agarose gel. The allele specific PCRs contain 2 lanes - one for wild type and the other for the variant allele. The genotyping was validated by dideoxy sequencing. Representative samples of each polymorphisms were confirmed by sequencing by outsourcing the sample.

Table 1: Demographic and clinical details of study group.

\begin{tabular}{|c|c|c|c|}
\hline & $\begin{array}{c}\text { Controls }(n=250) \\
\text { Mean } \pm \text { SD or } N(\%)\end{array}$ & $\begin{array}{c}\text { Cases }(n=250) \\
\text { Mean } \pm \text { SD or } N(\%)\end{array}$ & $p$-value \\
\hline Age(years) & $54 \pm 9$ & $53 \pm 8.3$ & 0.101 \\
\hline Gender & $167 \mathrm{M}: 83 \mathrm{~F}$ & $167 \mathrm{M}: 83 \mathrm{~F}$ & - \\
\hline Smoking & $37(14.8)$ & $38(15.2)$ & 0.841 \\
\hline Alcohol consumption & $52(20)$ & $51(20)$ & 0.864 \\
\hline Hypertension & $120(48)$ & $144(57)$ & 0.203 \\
\hline Diabetes & $74(29)$ & $116(46)$ & $0.019 *$ \\
\hline $\begin{array}{c}\text { Body mass index } \\
\text { Normal }\left(18-22.9 \mathrm{~kg} / \mathrm{m}^{2}\right) \\
\text { Overweight }\left(23-24.9 \mathrm{~kg} / \mathrm{m}^{2}\right) \\
\text { Obese }\left(>25 \mathrm{~kg} / \mathrm{m}^{2}\right)\end{array}$ & $\begin{array}{c}28(11.2) \\
33(13.2) \\
117(46)\end{array}$ & $\begin{array}{l}22(8.8) \\
23(9.2) \\
76(30)\end{array}$ & $\begin{array}{c}0.639 \\
0.365 \\
0.019 *\end{array}$ \\
\hline C/o Myocardial Infarction & - & $97(38.8)$ & - \\
\hline Family history of CAD & $58(23)$ & $100(40)$ & $0.009 *$ \\
\hline $\mathrm{TC}(\mathrm{mg} / \mathrm{dl})$ & $166 \pm 41$ & $167 \pm 46.6$ & 0.978 \\
\hline $\mathrm{TG}(\mathrm{mg} / \mathrm{dl})$ & $142 \pm 76.4$ & $142.5 \pm 65.9$ & 0.990 \\
\hline $\mathrm{HDL}-\mathrm{C}(\mathrm{mg} / \mathrm{dl})$ & $39 \pm 10$ & $36.8 \pm 10.6$ & 0.820 \\
\hline $\mathrm{LDL}-\mathrm{C}(\mathrm{mg} / \mathrm{dl})$ & $98.3 \pm 36$ & $100.7 \pm 39$ & 0.896 \\
\hline hsCRP(mg/dl), Median & 0.25 & 0.3 & $0.002^{*}$ \\
\hline sICAM1 level(ng/ml) & $410 \pm 142$ & $472.5 \pm 134.2$ & $0.0001 *$ \\
\hline
\end{tabular}

Citation: Chawla PK, Ponde CK, Rajani RM, Deshpande AS, Ashavaid TF, et al. (2020) Genetic Variants of Abo Blood Group and Coronary Artery Disease. J Cardiovasc Med Cardiol 7(2): 104-109. DOI: https://dx.doi.org/10.17352/2455-2976.000123 
Biochemical assay: Lipid profile including Total Cholesterol (TC), Triglycerides (TG) \& High density lipoproteins (HDL-C) were estimated from serum samples on DXC Unicell 800 Automated Analyser (Beckman Coulter) as per lab protocols. Low density lipoproteins (LDL-C) levels were calculated using the Friedwald's formula [17]. Inflammatory biomarkers like high sensitivity C- reactive protein (hsCRP) \& soluble intercellular cell adhesion molecule 1 (sICAM1) levels were estimated on DXC Automated analyser (Beckman Coulter) \& ELISA respectively.

Statistical analysis: Statistical analyses was done by MedCalc v.15.8. Normality testing was done using Shapiro-Wilk test. The normally distributed data was expressed as mean \pm standard deviation while those not normally distributed were expressed as median. Qualitative data was expressed in \%. Student's t-test or Mann Whitney test was used to compare the phenotypic variables between cases and controls while difference in genotype distribution between the groups was obtained using the chi-square test. Odds ratio was calculated to assess the risk in carriers $\mathrm{v} / \mathrm{s}$ non-carriers of significant variant alleles. A p-value of less than 0.05 was considered statistically significant.

\section{Results}

In the present study, $\mathrm{ABO}$ blood group alleles were studied in 250 CAD cases and 250 age and gender matched controls.

\section{Demographic details}

The demographic and clinical characteristics of the study group are described in Table 1.

The percentage of males and females in the study was $66.8 \%$ and $33.2 \%$ respectively. The mean age of the subjects was 53 years. Percentage of smokers and alcoholics were similar in cases and controls. Diabetes was an independent significant risk factor of CAD seen higher in cases over controls (46\% v/s 29\%; $\mathrm{p}=0.019)$. Hypertension was higher in cases than controls but was statistically insignificant $(57 \% \mathrm{v} / \mathrm{s} 48 \%$; $\mathrm{p}=0.203, \mathrm{NS}$ ). Obesity was significantly seen higher in controls over cases $(\mathrm{p}=0.019)$. Out of the 250 cases, 97 patients had a past or recent myocardial event and 41 patients had a past intervention (Angioplasty or bypass surgery). Family history was statistically significant with $40 \%$ cases and $23 \%$ controls having a positive family history $(\mathrm{p}=0.009)$.

Lipid profile was done for all study subjects. Among the lipid parameters, HDL-C levels were lower in cases $(36.8 \mathrm{mg} / \mathrm{dl})$ as compared to controls $(39 \mathrm{mg} / \mathrm{dl})$ however were statistically insignificant $(\mathrm{p}=0.820)$. TC, TG and LDL-C were similar between both groups. Among all biochemical parameters, only hsCRP was not normally distributed and hence expressed as median. Both the inflammatory markers, hsCRP and sICAM1 levels were significantly higher in cases than controls $(p=0.002$ $\& \mathrm{p}=0.0001$ respectively).

\section{Distribution of $A B O$ alleles \& blood group}

The distribution of $\mathrm{ABO}$ blood groups among cases and controls is given in Figure 1. The B allele was seen higher in cases as compared to controls (34\% v/s $19 \%$; $\mathrm{p}=0.01$ ) while the $\mathrm{O} 1$ alleles was higher in controls than cases (48\% v/s 32\%; $\mathrm{p}=0.02$ ). The remaining $\mathrm{A} 1, \mathrm{~A} 2$ and $\mathrm{O} 2$ allele were almost equally distributed between cases and controls. Similarly, phenotypically, the B blood group was significantly higher in cases as compared to controls ( $37 \% \mathrm{v} / \mathrm{s} 24 \%$; $=0.04)$ while the $\mathrm{O}$ blood group was higher in controls than cases $(37 \% \mathrm{v} / \mathrm{s}$ $22 \% ; \mathrm{p}=0.02$ ). The $\mathrm{A}$ and $\mathrm{AB}$ blood groups were uniformly distributed in cases and controls.

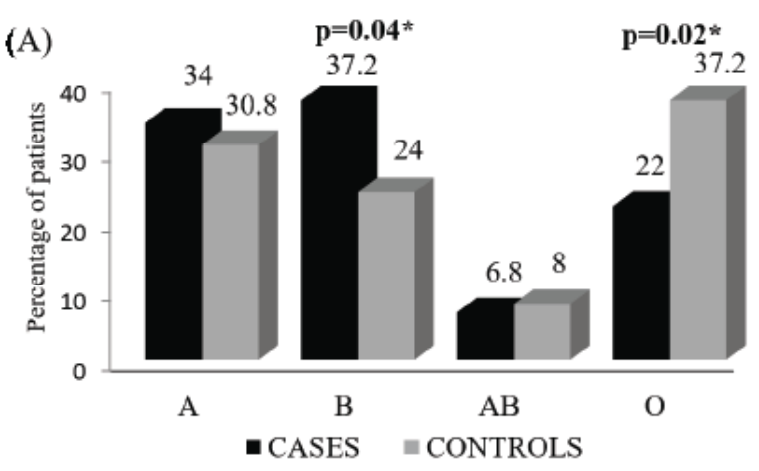

(B)

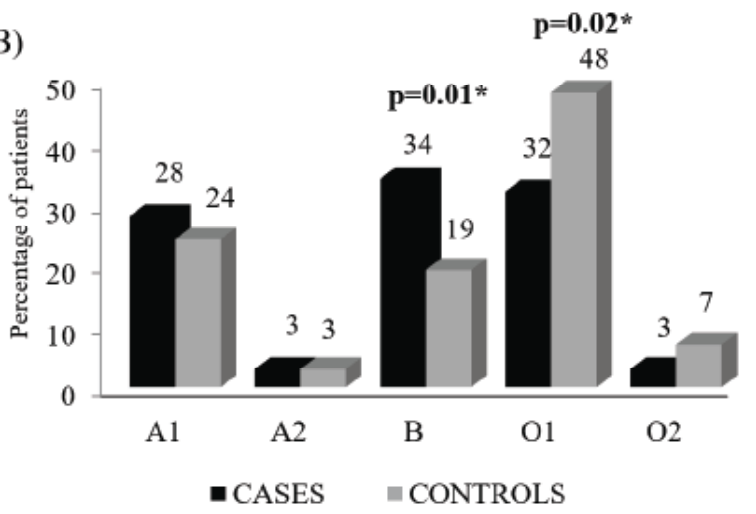

Figure 1: Distribution of ABO blood groups between cases and controls. (A) Allele frequencies of $A B O$ alleles (B) Phenotypic distribution of $A B O$ blood groups.

\section{Prevalence of $\mathrm{ABO}$ genotypes}

Among the 15 possible genotypes, the $\mathrm{A} 2 \mathrm{~A} 2$ and $\mathrm{O} 2 \mathrm{O} 2$ were not seen in the entire study group while the $\mathrm{A} 2 \mathrm{O} 2$ genotype was seen in only 1 control. The distribution of the genotypes between cases and controls is described in Table 2. The BB genotype was seen significantly higher in cases as compared to controls $(24 \% \mathrm{v} / \mathrm{s} 6 \% ; \mathrm{p}=0.0002)$ increasing the risk of CAD by 5 folds (OR=4.66; 95\% CI: 1.9-11.3) while the 0101 genotype was higher in controls than cases ( $31 \% \mathrm{v} / \mathrm{s} 19 \% ; \mathrm{p}=0.05)$ reducing the risk of CAD by 2 folds (OR= 1.91; 95\% CI: 0.993.6). The other genotypes were similarly distributed in cases and controls.

\section{Statistically significant}

Association of B allele with risk factors for CAD: Of the 5 alleles studied, the B allele was significantly higher in cases than controls suggesting an atherogenic role. The risk of CAD was further evaluated among the variant allele carriers and other known CAD risk factors (Figure $2 \mathrm{~A}$ ). 
It was observed that in presence of $\mathrm{B}$ variant allele, diabetes $(p=0.006)$, family history of CAD $(p=0.025)$ and low HDL $(p=0.033)$, were independently associated risk factors for CAD. The risk of development of CAD increases by 3 folds in diabetics (OR-2.7, \%95 CI= 1.5-4.75) while that in presence of family history increases by 2 folds (OR-2.06, \%95 CI= 1.083.9). Amongst the lipid profile, the risk of disease progression increases by 2 folds with low levels of HDL (OR-1.83, \%95 CI=

Table 2: Distribution of ABO Genotypes between cases and controls.

\begin{tabular}{|c|c|c|c|}
\hline Genotype & Controls, N(\%) & Cases, N(\%) & $\begin{array}{c}\text { p-value } \\
\text { Odds ratio(95\% CI) }\end{array}$ \\
\hline A1A1 & $31(12)$ & $46(18)$ & 0.240 \\
\hline A1A2 & $3(1)$ & $7(3)$ & 0.999 \\
\hline A101 & $32(13)$ & $24(10)$ & 0.507 \\
\hline A102 & $1(0.5)$ & $3(1)$ & - \\
\hline A201 & $7(3)$ & $5(2)$ & 0.999 \\
\hline A202 & $1(0.5)$ & $0(0)$ & $0.0008 *$ \\
\hline BB & $16(6)$ & $60(24)$ & 0.300 \\
\hline B01 & $39(16)$ & $27(11)$ & 0.999 \\
\hline B02 & $5(2)$ & $6(2)$ & 0.554 \\
\hline A1B & $17(7)$ & $12(5)$ & 0.999 \\
\hline A2B & $5(2)$ & $5(2)$ & $0.050^{\star}$ \\
\hline 0101 & $66(31)$ & $48(19)$ & 0.194 \\
\hline 0102 & $27(6)$ & $7(3)$ & $0.91(1-3.6)$ \\
\hline
\end{tabular}
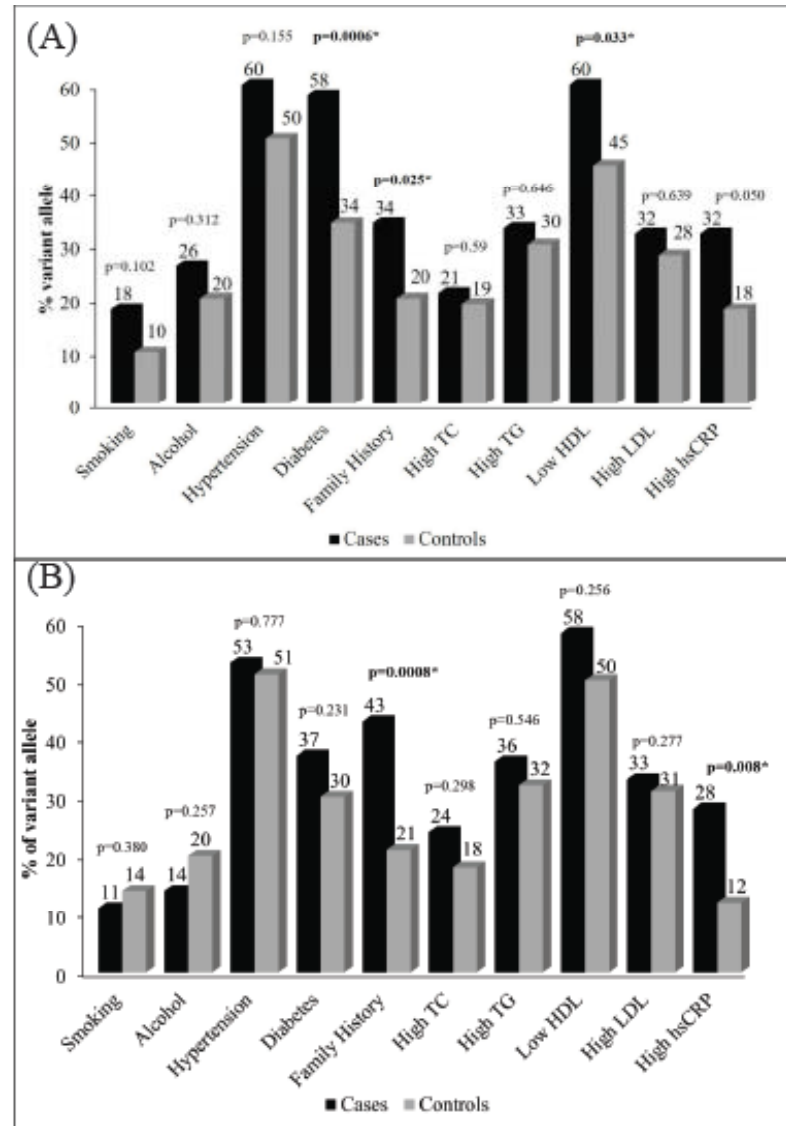

Figure 2: Distribution of variant allele between cases and controls with CAD risk factors (A) B allele (B) 01 allele (* Statistically significant with $p<0.05$ ).
1.1-3.2). Since age and gender are two non-modifiable risk factors for $\mathrm{CAD}$, the role of $\mathrm{B}$ allele was studied in these patients too. Majority of patients ( $75 \%, 83$ cases and 60 controls) were in the older age group ( $>50$ years) while remaining quarter $(25 \%$, 27 cases and 21 controls) were in the young age group $(<50$ years). The number of cases and controls in each group were similar and hence statistically insignificant. The frequency of males in the study group was almost double than females. The number of females carrying the variant $B$ allele were similar in cases and controls ( $\mathrm{n}=31$ in each group) while carriers of the variant $\mathrm{B}$ allele were significant in males increasing the risk of CAD by 2 folds ( $47 \% \mathrm{v} / \mathrm{s} 31 \%$; $\mathrm{p}=0.002$; OR=1.9).

\section{Association of 01 allele with risk factors for CAD}

The risk of CAD was further evaluated among the variant O1 allele carriers and other known CAD risk factors (Figure 2B) among cases \& controls. In presence of the $\mathrm{O} 1$ allele, only family history of CAD $(\mathrm{p}=0.0008)$ plays a significant role for developing the risk of CAD by 2 folds (OR-2.06, \%95 CI=1.083.9) while high hsCRP $(p=0.008)$ further increased the risk by 3 folds (OR-2.83, \%95 CI= 1.35-6.0). Other factors like diabetes, high TC, was seen higher in cases as compared to controls, however, statistically insignificant. In this group too, majority of patients ( $74 \%, 82$ cases and 126 controls) were in the older age group ( $>50$ years) while remaining quarter $(26 \%, 29$ cases and 46 controls) were in the young age group ( $<50$ years). The number of cases and controls in each age group were similar and hence statistically insignificant. About 179 males ( 71 cases $\& 107$ controls) decreasing the risk of CAD by 3 folds ( $p=0.0001$; $\mathrm{OR}=2.6$ ) and 105 females ( 40 cases \& 65 controls) carried the variant $\mathrm{O} 1$ allele, however, insignificant.

sICAM1 levels were significantly seen higher in cases over controls in the entire study group $(\mathrm{p}=0.0001)$. However, on comparing within the blood groups, the levels were insignificant. The variant allele carriers showed elevated levels of sICAM1 among the cases as compared to controls however, the difference was statistically insignificant.

\section{Discussion}

The clinical role of $\mathrm{ABO}$ blood group has been widely reported in several diseases like cardiovascular events. Several GWAS have identified the ABO locus to be associated with soluble levels of inflammatory markers like adhesion molecules and selectins. In this study, we aimed to associate the role of genetic variants of $\mathrm{ABO}$ gene that determine the $\mathrm{ABO}$ blood group with $\mathrm{CAD}$ and its risk factors. Our study included 500 subjects who underwent coronary catherization for coronary angiography. The 250 proven CAD patients with > $50 \%$ stenosis in atleast one of the major coronary arteries were age and gender matched with angiographically proven negative controls.

In our study group, diabetes $(p=0.019)$, family history of $\operatorname{CAD}(\mathrm{p}=0.009), \operatorname{hsCRP}(\mathrm{p}=0.002)$ and sICAM1 levels $(\mathrm{p}=0.0001)$ were found to be independent risk factors for development of CAD. Diabetes is a prime risk factor for cardiovascular disease (CVD). Hyperglycaemia, a hallmark of diabetes affects the heart muscle, causing both systolic and diastolic heart failure. Insulin 
deficiency or defective insulin signalling (insulin resistance) in endothelial cells decrease the bioavailability of NO, a potent vasodilator, as well as increased secretion of the vasoconstrictor endothelin-1 [16]. This process leads to release of proinflammatory cytokines, initiation of endothelial dysfunction and hence inflammation. Inflammation is a normal response to endothelial tissue injury involves the activation of leukocytes mediated, in part, by a family of cytokines and chemokines. Diabetes has long been considered a state of chronic, low-level inflammation, and there is some evidence to suggest that this immune activation may precede insulin resistance in diabetic and pre-diabetic states and ultimately may be the factor that initially increases cardiovascular risk in these disease processes $[16,17]$. Recent evidence suggests crosstalk between the molecular pathways involved in both inflammation and insulin signalling, and this cross-talk may provide clues to the strong relationship between insulin-resistant states (such as the metabolic syndrome and type 2 diabetes), inflammation, and CAD [16-18]. Proinflammatory cytokines cause or exacerbate injury by a variety of mechanisms including enhanced vascular permeability, programmed cell death (apoptosis), recruitment of invasive leukocytes, and the promotion of reactive oxygen species (ROS) production and hence initiation of fatty streak and plaque formation.

In the current study, genotyping of variants of $\mathrm{ABO}$ gene that determine the blood type A1 allele, A2 allele (Deletion of C), B allele (G803C), O1 (Deletion of G) and $\mathrm{O} 2$ allele (G802A) was performed by conventional PCR methods. Of these the $\mathrm{B}$ allele was significantly seen higher in cases than controls while the $\mathrm{O} 1$ allele was significantly higher in controls than cases. The remaining A1, A2, $\mathrm{O}_{2}$ alleles were similar between CAD cases and controls and hence insignificant.

Prior to DNA analysis of the ABO gene, serological analyses have been the practical way to determine the blood groups. These tests were based on the principle of either the presence or absence of the A or B antigens on RBCs or the presence or absence of IgM anti-A or anti-B in the serum or plasma. About $70 \mathrm{ABO}$ alleles are reported to the Blood group Antigen Gene Mutation Database, "dbRBC" [10]. Majority of these alleles are uncommon while few are formed by recombination between the $A B O$ alleles. The frequencies of these alleles also differ accordingly to different geographic and ethnic groups [10]. The 5 major alleles prevalent in most ethnic groups and especially in Asians are A1, A2, O1, $\mathrm{O} 2$ and the $\mathrm{B}$ alleles. The phenotype $A, B, A B$ or $O$ blood groups are defined by the genotypic combinations of these alleles. An individual can have the $\mathrm{O}$ allele as well as non- $\mathrm{O}$ allele in heterozygous conditions, however, following the co-dominance pattern of inheritance, the phenotype will be a non-O blood group.

Numerous literature reports of association of blood groups with $\mathrm{CAD}$ are available however, they are restricted to serological testing of blood groups. However, the structure \& expression of the blood groups may be influenced by the presence of the type of $\mathrm{ABO}$ alleles. There is scarcity of data on genotypic association of $\mathrm{ABO}$ blood groups with $\mathrm{CAD}$. In our study, we observed the $\mathrm{BB}$ genotype to be at the highest risk for CAD with an odds ratio of 4.66 (95\% CI - 1.9 - 11.3) i.e. 4.6 folds higher risk. The $\mathrm{B}$ phenotype is defined by the $\mathrm{BB}$, $\mathrm{BO} 1 \& \mathrm{BO} 2$ genotypes and our study reflects of all the three combinations, the BB genotypes is at highest risk. We also observed among the B variant carriers, diabetes, family history of premature $\mathrm{CAD}$ and low HDL were independent risk factors. Thus, the risk of CAD among the B variant carriers with any of the above traditional risk factor increases proportionally. Jukic et al found the $\mathrm{A} 1 \mathrm{~B}, \mathrm{~A} 2 \mathrm{~B}$ genotypes followed by the $\mathrm{BB}$, $\mathrm{O} 1 \mathrm{~B}$ and $\mathrm{O} 2 \mathrm{~B}$ genotypes at high risk for thrombosis in Croatian population with a 2 fold increased risk [19]. Several studies report the non-O blood group to be associated with CAD than the $\mathrm{O}$ blood group. Carpeggiani et al found the non-O group is associated with increased mortality in patients with ischaemic heart disease. The $\mathrm{A} \& \mathrm{~B}$ blood group individuals were at a higher risk for MI than the O blood group [20]. Sharif et al reported the A blood group to be at high risk for ischaemic heart disease in Pakistani population. Among the 200 ischaemic heart disease patients compared with 230 controls blood group A was found to be at highest risk for $\mathrm{CAD}$ followed by $\mathrm{B}, \mathrm{O}$ and least $\mathrm{AB}$ [21].

The $\mathrm{O} 1$ allele was seen higher in controls over cases in our study. Presence of $\mathrm{O} 1$ allele carriers reduce the risk of CAD by 2 folds (odds ratio 1.91; 95\% CI: 0.99-3.6). Our findings are in concordance with literature reflecting the $\mathrm{O}$ blood group playing an athero-protective role in presence of other risk factors as well. The $\mathrm{O} 1$ allele may be present in either heterozygous or homozygous conditions. Thus, in A or B blood groups phenotypes where the $\mathrm{O} 1$ allele is present in heterozygous condition, the protective role of this variant shields the individual from developing severe CAD. Family history of CAD is an independent risk factor for CAD in presence of $\mathrm{O} 1$ allele. hsCRP, an early biomarker of inflammation was high in cases compared to controls. However, this may also suggest the tendency of controls to develop CAD as they age [22-24].

A limitation of the study is the small sample size, which is further reduced during subgrouping of individual blood groups. Further studies in larger Indian cohorts are needed to be carried out to validate these results and understand the clinical role of blood groups with pathways involved in CAD progression.

\section{Conclusion}

Among the ABO blood group alleles, this study has identified the $\mathrm{B}$ variant allele playing an atherogenic role while the $\mathrm{O} 1$ allele playing an athero-protective role. These variants may be present in homozygous or heterozygous forms in individual genotypes thus implicating differed severity risk on individuals. Thus, genetic screening of patients for evaluating risk of CAD will help individuals at high risk of disease progression \& better preventive management.

\section{Acknowledgements}

This work was funded by National Health and Education Society (NHES) of P. D. Hinduja National Hospital and Medical Research Centre. The authors are grateful to all study subjects for their participation in the study.

Citation: Chawla PK, Ponde CK, Rajani RM, Deshpande AS, Ashavaid TF, et al. (2020) Genetic Variants of Abo Blood Group and Coronary Artery Disease. J Cardiovasc Med Cardiol 7(2): 104-109. DOI: https://dx.doi.org/10.17352/2455-2976.000123 


\section{Funding}

This work was funded by National Health and Education Society (NHES) of P. D. Hinduja Hospital and Medical Research Centre.

\section{References}

1. Tan ST, Scott W, Panoulas V, Sehmi J, Zhang W, et al. (2014) Coronary heart disease in Indian Asians. Glob Cardiol Sci Pract 4: 13-23. Link: https://bit.ly/2LerVdq

2. Trenkwalder T, Kessler T, Schunkert H, Erdmann J (2015) Genetics of coronary artery disease: Short people at risk? Expert Rev Cardiovasc Ther 13: 11691172. Link: https://bit.ly/2zmus2y

3. Holmes MV, Shah SH, Angelakopoulou A, Khan T, Swerdlow D, et al. (2009) Complex disease genetics: present and future translational applications. Genome Med 1: 104. Link: https://bit.ly/2WCsAeb

4. Mannarino E, Pirro M (2008) Molecular biology of atherosclerosis. Clin Cases Miner Bone Metab 5: 57-62. Link: https://bit.ly/2L7bxf0

5. Reilly M, Li M, He J, Ferguson J (2011) Novel locus for coronary atherosclerosis and association of $\mathrm{ABO}$ with myocardial infarction in the presence of coronary atherosclerosis: two genome-wide association. Lancet 377: 383-392.

6. Adamo PJD (2015) Diet, Disease and the ABO Blood Groups. Link: https://bit.ly/2WcmiTq

7. Ehret GB, Munroe PB, Rice KM, Bochud M, Johnson AD, et al. (2011) Genetic variants in novel pathways influence blood pressure and cardiovascular disease risk. Nature 478: 103-109. Link: https://bit.ly/2Lc9giw

8. Allan TM, Dawson AA (1968) ABO Blood Groups and Ischaemic Heart Disease in Men. Br Heart J 30: 377-382. Link: https://bit.ly/3bbilgR

9. Liumbruno GM, Franchini M (2013) Beyond immunohaematology: The role of the ABO blood group in human diseases. Blood Transfus 11: 491-499. Link: https://bit.ly/2SJrKLG

10. Patnaik SK, Helmberg W, Blumenfeld OO (2012) BGMUT: NCBI dbRBC database of allelic variations of genes encoding antigens of blood group systems. Nucleic Acids Res 40: D1023-D1029. Link: https://bit.ly/2WAbEFf

11. Etemadi A, Kamangar F, Islami F, Poustchi H, Pourshams A, et al. (2015) Mortality and cancer in relation to $\mathrm{ABO}$ blood group phenotypes in the Golestan Cohort Study. BMC Med 13: 8. Link: https://bit.ly/3bcdYY3

12. Zhang H, Mooney CJ, Reilly MP (2012) ABO Blood Groups and Cardiovascular Diseases. Int J Vasc Med 2012: 641917. Link: https://bit.ly/2LdeFGd

13. Barbalic M, Dupuis J, Dehghan A, Bis JC, Hoogeveen RC, et al. (2010) Large scale genomic studies reveal central role of $A B O$ in sP-selectin and SICAM-1 levels. Hum Mol Genet 19: 1863-1872. Link: https://bit.ly/3bbOQkh

14. Paterson AD, Lopes-Virella MF, Waggott $D$, Boright AP, Hosseini SM, et al. (2009) Genome-wide association identifies the ABO blood group as a major locus associated with serum levels of soluble E-selectin. Arterioscler Thromb Vasc Biol 29: 1958-1967. Link: https://bit.ly/2YR6BCO

15. Karakas M, Baumert J, Kleber ME, Thorand B, Dallmeier D, et al. (2012) A Variant in the Abo Gene Explains the Variation in Soluble E-Selectin LevelsResults from Dense Genotyping in Two Independent Populations. PLoS One 7: e51441. Link: https://bit.ly/3dmIOi8
16. Dokken BB (2008) The Pathophysiology of Cardiovascular Disease and Diabetes: Beyond Blood Pressure and Lipids. Diabetes Spectr 21: 160-165. Link: https://bit.ly/2L7WZf2

17. Mudau M, Genis A, Lochner A, Strijdom H (2012) Endothelial dysfunction: the early predictor of atherosclerosis. Cardiovasc J Afr 23: 222-231. Link: https://bit.ly/3chl2Ed

18. Willerson JT, Ridker PM (2004) Inflammation as a cardiovascular risk factor Circulation 109: Il2-10. Link: https://bit.ly/2yGCGCT

19. Jukic I, Bingulac-Popovic J, Dogic V, Babic I, Culej J, et al. (2009) ABO blood groups and genetic risk factors for thrombosis in Croatian population. Croat Med J 50: 550-558. Link: https://bit.ly/3dq6lt7

20. Carpeggiani C, Coceani M, Landi P, Michelassi C, L'abbate A (2010) ABO blood group alleles: A risk factor for coronary artery disease. An angiographic study. Atherosclerosis 211: 461-466. Link: https://bit.ly/2AdouBT

21. Sharif S, Anwar N, Farasat T, Naz S (2014) ABO blood group frequency in Ischemic heart disease patients in Pakistani population. Pak J Med Sci 30: 2013-2015. Link: https://bit.ly/3cfNWEB

22. Thakur S, Gupta S, Parchwani H, Shah V, Yadav V (2011) Hs-CRP - A Potential Marker for Coronary Heart Disease. Indian J Fundam Appl Life Sci 1: 1-4. Link: Link: https://bit.ly/2L7lt79

23. Naitza S, Porcu E, Steri M, Taub DD, Mulas A, et al. (2012) A genome-wide association scan on the levels of markers of inflammation in sardinians reveals associations that underpin its complex regulation. PLoS Genet 8 : e1002480. Link: https://bit.ly/2La3E8H

24. Chen Z, Yang S, Xu H, Li J (2016) ABO blood group system and the coronary artery disease: an updated systematic review and meta-analysis. Sci Rep 6 Link: https://bit.ly/3cgNUwv

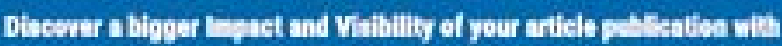 Peertechr Publleations \\ Highwghts \\ - Sipnatsry putanet af ONoD \\ - Sonatsy Rutisher of DCFA (Ban Francisos Detarates an Research Assessment

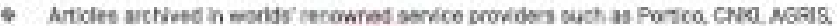

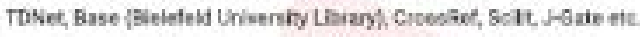

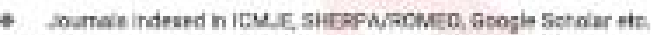

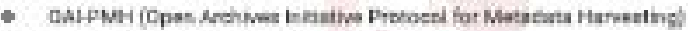 \\ * Deticated Eshoris Baerti for mary journa \\ - Acturate and rapid peecreview prosts: \\ - hereasad etobions of putlishad articles through promobiens \\ - Recuoed tmelhe sor article pibilication

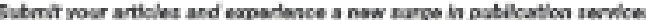 (Mitps:Srww peertachz ecro/nubmissbon)

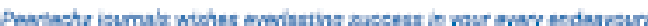

Copyright: (c) 2020 Chawla PK, et al. This is an open-access article distributed under the terms of the Creative Commons Attribution License, which permits unrestricted use, distribution, and reproduction in any medium, provided the original author and source are credited.

Citation: Chawla PK, Ponde CK, Rajani RM, Deshpande AS, Ashavaid TF, et al. (2020) Genetic Variants of Abo Blood Group and Coronary Artery Disease. J Cardiovasc Med Cardiol 7(2): 104-109. DOI: https://dx.doi.org/10.17352/2455-2976.000123 